\title{
TRANSIENT HEART BLOCK AND CORONARY OCCLUSION IN PLEURAL SHOCK
}

\author{
BY \\ D. R. CAMERON \\ Received February 27, 1945
}

Pleural shock is, happily, a rare accident. Anderson (1936) estimates that it occurs once in 2000 refills, and that the fatality rate may vary from 15 to 50 per cent. Ormond (1942), reviewing the reported cases, considers it less common. Be that as it may, it is an alarming happening.

This case, in which syncope occurred during an attempted artificial pneumothoraxinduction, has unusual features; and some explanation of what occurred will be attempted, though no final conclusions can be drawn.

\section{CASE Notes}

An attempt was made to induce an artificial pneumothorax in a woman of 24 with tuberculous infiltration of the left upper lobe. The two layers of pleura were found to be adherent, so the attempt was abandoned and she was returned to the ward. A few minutes later she complained of faintness and difficulty in breathing; she became pale, cold, and clammy, with cyanosed lips and dilated pupils; and soon shewas unconscious. The respirations were deep and sighing, and the neck veins moderately distended; the pulse could not be felt at the wrist and auscultation showed a slow heart rate. Fig. 1A, taken at this stage, showed complete heart block with a ventricular rate of 44 . Atropine sulph., 1/100 of a grain, was given intravenously, and the pulse rate increased in four minutes to 120 a minute. After fifteen minutes Fig. 1B showed normal rhythm at a rate of 65 a minute. Clinical improvement quickly followed the increase in her pulse rate. She soon regained consciousness and in about an hour she seemed reasonably well again. At no time, then or later, did she complain of pain. Five weeks later another electrocardiogram was taken: this, surprisingly, showed strong evidence of a T I type of coronary occlusion. Subsequent records were typical of what might be expected in the gradual return of a coronary curve towards normal. Five months after her attack, she was transferred to a sanatorium in another part of the county with a view to thoracoplasty, but this was not done, and she has since died of pulmonary tuberculosis. This, therefore, seems to be an example of pleural shock with subsequent coronary damage.

\section{Discussion}

Pleural Shock. This has been attributed either to a vagal reflex or to air embolism. Opinions differ as to which is the more common and important cause. Cocke $(1931,1935)$, for instance, considers that it is most commonly a reflex syncope, while Rukstinat (1931) believes that the symptoms are generally the result of air embolism. Forbes (1944), quoting Hamilton and Rothstein, and Chase, in support of his opinion, agrees with Rukstinat. It is evident, however, as Ormond (1942) concludes, that there are two forms of pleural shockone being a reflex syncope and the other due to air embolism. The former appears to resemble, clinically, an ordinary fainting attack such as has been discussed recently in blood donor clinics. (M.R.C. Report, 1944). That the latter does occur there can be no doubt, the evidence being the cases that have been reported with cerebral symptoms and hemiplegia, 

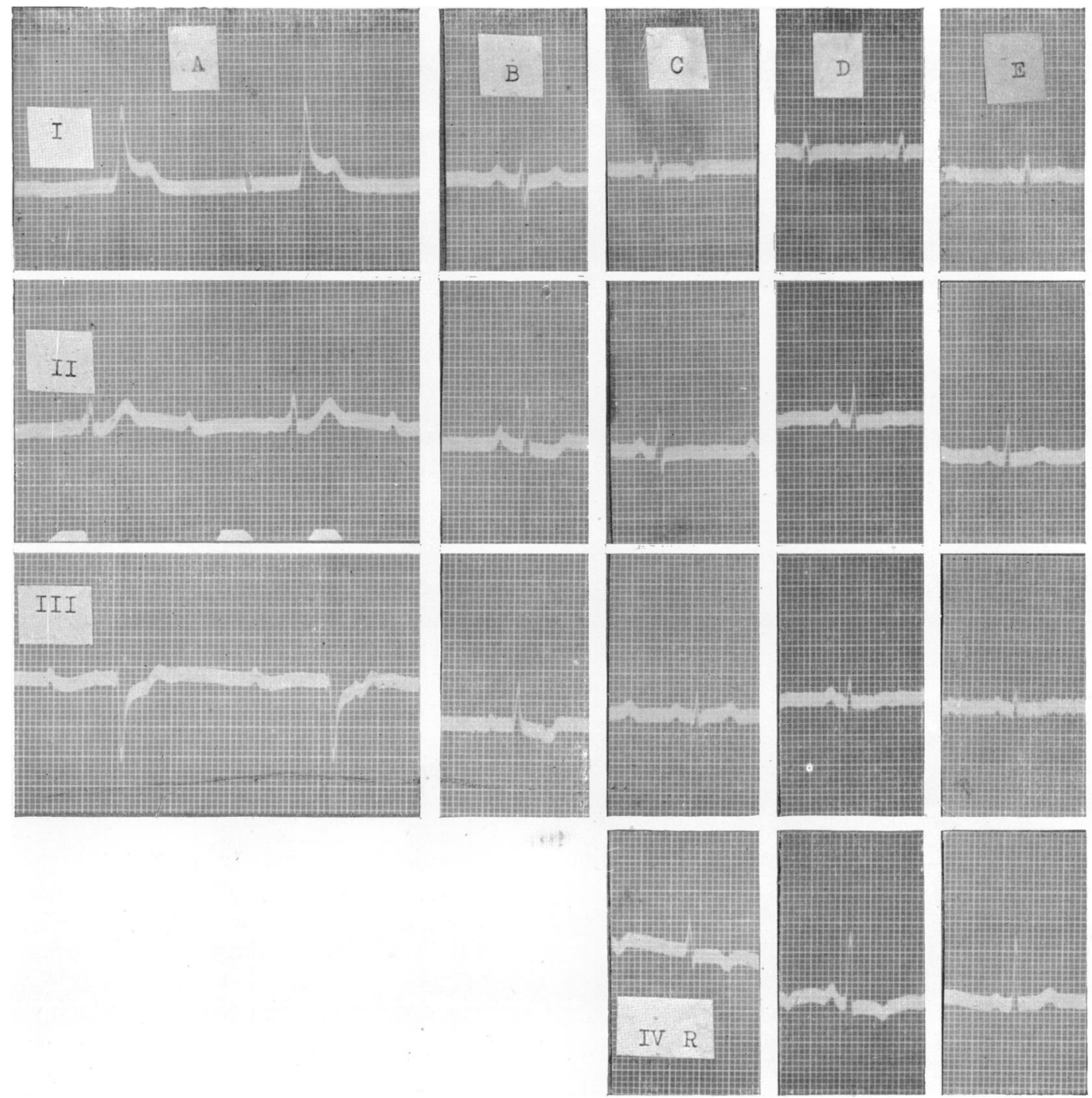

FIG. 1.

(A) 19/6/44. Complete heart block, ventricular rate 44, auricular rate 98. Bizarre QRS-T complex in leads I and III. QRS II, 0.08 sec., S-T II depressed $0.5 \mathrm{~mm}$., T positive, $3.5 \mathrm{~mm}$. (B) $19 / 6 / 44$, fifteen minutes later. Resumption of normal rhythm, rate 65; P-R interval, $0 \cdot 2$ sec.; right axis deviation, and T III inverted. (C) 28/7/44. Development indicating occlusion of anterior coronary, T I, type. (D) 12/9/44. Regression. T I now flat, T IV still inverted. (E) 17/10/44. T I and T IV now upright, low voltage in limb leads.

the post-mortem demonstration of air in the cerebral and, sometimes, in the coronary arteries, and the clinical signs of air embolism occasionally seen during life in the retinal arteries.

Complete Heart Block. This is most often due to an intrinsic myocardial lesion (Parkinson, Papp, and Evans, 1941), though rarely, as described by Weiss and Ferris (1934), it may be reflex. Comeau (1937), discussing paroxysmal complete block, attributes most cases to coronary sclerosis. There may, again, be a contributory vagal factor as well as a basis of sclerosis, as in Starling's (1921) case which Comeau quotes; here Stokes-Adams seizures were arrested by atropine.

It is possible, therefore, that in my case, as normal rhythm was quickly restored after atropine, some vagal factor was present; yet it must be admitted that normal rhythm might have been resumed in any case.

It is well known (Katz 1941, and others), that complete heart block may mark the onset of 
an acute coronary occlusion. It is doubtful whether atropine would restore normal rhythm in those circumstances.

Coronary Embolism. The great majority of acute coronary occlusions must be due to thrombosis. A number of cases caused by various emboli has been collected and extended by Porter and Vaughan (1940). No mention of air embolism is made. In all the cases they describe, præcordial pain was a feature, and a cardiogram of one of them shows a T I type of coronary curve.

Durant (1934), however, describes a probable case of coronary air embolism, with cardiographic evidence of a T I type of coronary occlusion. Here some complaint of substernal oppression was made, but syncope and a generalized convulsion were the most prominent features.

\section{SUMMARY}

In the case here described, heart block existing during the acute phase may have been due partly to a vagal reflex, yet a more important factor, from the subsequent cardiogram would appear to have been a coronary occlusion. The possibility of acute coronary insufficiency without occlusion, as described by Master (1944), is not a likely one; his cardiograms do not resemble those here described. It is hardly likely that a coincident coronary thrombosis took place. The close association with the attempted pneumothorax induction, together with the age of the patient, make this extremely unlikely. A wound of the heart can be excluded: the needle was never deep enough to have produced this. A clot disturbed from a thrombotic process in the pulmonary circulations might produce an embolism (Saphir, 1933) and this remains a possibility. It seems more reasonable to assume that an air embolism occurred.

Fig. 1B shows, curiously, right axis deviation, without a coronary type of curve. As the typical changes indicative of coronary occlusion may take some little time to develop-up to a few hours (White, 1931) - this right axis deviation may have existed before the accident, as in Durant's case. Fig. 1C, D, and E leave little doubt that recovery was taking place from myocardial infarction.

An interesting point is the absence of pain. Pain is evidently not one of the main features of this form of pleural shock. It may be that this absence of pain is a clinical characteristic of coronary air embolism, in contradistinction to other types of occlusion.

Heart block may occur more commonly in pleural shock than is thought, and Cocke remarks on bradycardia in two of his cases.

It is suggested that in the case here reported, coronary air embolism occurred producing transient heart block and myocardial infarction.

I have to thank Dr. John Parkinson for many helpful suggestions about this case.

\section{REFERENCES}

Anderson, D. L. (1936). Virg. Med. Month., 63, 371.

Cocke, C. H. (1931). Amer. Rev. Tuberc., 24, 545.

- (1935). Ibid., 31, 404.

Comeau, W. J. (1937). Amer. J. med. Sci., 194, 43.

Durant, T. M. (1934). Annals intern. Med., 8, 1625.

Forbes, G. (1944). Brit. med. J., 2, 529.

Katz, L. N. (1941). Electrocardiography, London, p. 475.

Master, A. M., Jaffe, H. L., Dack, S., and Grishman, A. M. (1944). Amer. Heart J., $27,803$.

Medical Research Council Report (1944). Brit. med. J., 1, 279.

Ormond, A. L. (1942). $\quad$ North Carolina med. J., 3, 623.

Parkinson, J., Papp, C., and Evans, W. (1941). Brit. Heart J., 3, 171.

Porter W. B., and Vaughan, E. W. (1940). Amer. J. med. Sci., 200, 184.

Rukstinat, G. (1931). J. Amer. med. Ass., 96, 26.

Saphir, O. Amer. Heart J. (1933), 8, 312.

Starling, J. H. (1921). Heart, 8, 31 .

Weiss, S., and Ferris, E. B. (1934). Arch. intern. Med., 54, 931.

White, P. D. (1931). Heart Disease, New York, p. 422. 